\title{
Directed evolution by UV-C treatment of Bacillus cereus spores
}

Katrien Begyn ${ }^{1 *}$, Tom Dongmin Kim² ${ }^{2}$, Marc Heyndrickx ${ }^{3,4}$, Chris Michiels ${ }^{2}$, Abram Aertsen ${ }^{2}$, Andreja Rajkovic $^{1} \&$ Frank Devlieghere ${ }^{1}$

${ }^{1}$ Research unit Food Microbiology and Food Preservation (FMFP-UGent), Department of Food Technology, safety and health, Faculty Bioscience Engineering, Ghent University (Ghent, Belgium)

${ }^{2}$ Laboratory of Food Microbiology, Department of Microbial and Molecular systems (M ${ }^{2} S$ ), Faculty of Bioscience Engineering, KU Leuven (Leuven, Belgium)

${ }^{3}$ ILVO - Flanders Research Institute for Agriculture, Fisheries and Food, Technology and Food Science, Unit - Food Safety (Melle, Belgium)

${ }^{4}$ Department of Pathology, Bacteriology and Avian Diseases, Faculty of Veterinary Medicine, Ghent University (Merelbeke, Belgium)

*These two authors have contributed equally to this article.

Contact:

Frank Devlieghere (1) \& Abram Aertsen (2)

frank.devlieghere@ugent.be

abram.aertsen@kuleuven.be

(1) Research unit Food Microbiology and Food Preservation (FMFP-UGent), Department of Food Technology, safety and health, Faculty Bioscience Engineering, Ghent University (Ghent, Belgium)

Coupure Links 653

9000 Gent

Belgium

(2) Laboratory of Food Microbiology, Department of Microbial and Molecular systems ( $\left.{ }^{2} S\right)$, Faculty of Bioscience Engineering, KU Leuven 


\section{Abstract}

2 Bacterial endospores are exposed to a broad variety of sublethal and lethal stresses in the food

3 production chain. Generally, these stresses will not completely eliminate the existing spore

4 populations, and thus constitute a selection pressure on the spores. One stress that is frequently

5 used in the food production chains to disinfect (food) contact surfaces is UV-C. At a wavelength of

$6254 \mathrm{~nm}, \mathrm{UV}-\mathrm{C}$ has germicidal properties. The aim of this research is to investigate the impact of UV-C

7 stress on the evolution of endospore recalcitrance and germination in B. cereus.

8 A directed evolution experiment was set up in which B. cereus was repeatedly subjected to a cycle of sporulation, sporicidal UV-C treatment, germination and outgrowth. We show here that three independent lineages of UV-C cycled B. cereus spores reproducibly acquired a 30-fold or higher increase in UV-C resistance at $164 \mathrm{~mJ} / \mathrm{cm}^{2}$. Surprisingly, the UV-C resistant spores of the clones isolated from each of the lineages also became significantly more sensitive to wet heat as a normally non-lethal heat treatment at $70^{\circ} \mathrm{C}$ for 15 minutes resulted in an average $1.8 \log \mathrm{cfu} / \mathrm{mL}$ reduction. From time-lapse phase contrast microscopy analysis, UV-C resistant mutant spores also showed a distinctive heterogeneity in refractility and a severe germination defect compared to the wild type. However, UV-C resistance of the corresponding vegetative cells were not altered. In conclusion, this work shows that UV-C resistance of endospores is an adaptive trait that can readily be improved, although at an apparent cost for heat resistance and germination efficiency. As such, these results provide novel insights in the evolvability of, and correlation between, some endospore properties. microscopy; stress cycling

\section{Introduction}


Bacillus cereus endospores are very resistant to heat, dehydration and other physical stresses. They are able to survive in soil, sediments and dust (Nicholson et al., 2000; Stenfors Arnesen et al., 2008; Wassmann et al., 2012, 2010). As the spores of $B$. cereus are omnipresent in the environment, they find their way into the food processing plants and final food products (Carlin, 2011; Heyndrickx, 2011; Soni et al., 2016; Wells-Bennik et al., 2016). Upon germination and outgrowth some of the $B$. cereus strains can cause food spoilage or food poisoning, as most strains of $B$. cereus are toxin producers. B. cereus can cause two types of syndromes: (i) the emetic syndrome caused by the emetic toxin cereulide, or (ii) the diarrheal syndrome caused by one or more enterotoxins. At least three toxins are implicated in the diarrheal syndrome, namely haemolysin $\mathrm{BL}(\mathrm{Hbl})$, nonhaemolytic enterotoxin (Nhe) and cytotoxin K (CytK)(Fagerlund et al., 2008; Ganash et al., 2013; Lund et al., 2000; Stenfors Arnesen et al., 2008).

Food producers need to eliminate $B$. cereus or prevent their outgrowth to avert spoilage and foodborne disease. Bacterial endospores are exposed to a broad variety of sublethal and lethal stresses in the food production chain (Carlin, 2011; Heyndrickx, 2011; Stenfors Arnesen et al., 2008). Often, these stresses do not completely eliminate the existing spore populations, and thus constitute a selection pressure on the spores (Eijlander et al., 2011; Warda et al., 2015).

Endospores are highly resistant as their multi-layered endospore structure protects the DNA, ribosomes and spore enzymes, which can be found inside the core. The core has a low water content but is packed with the spore-specific molecule pyridine-2,6-dicarboxylic acid (dipicolonic acid, DPA). From the inside to the outside, the following layers can be found: core, inner spore membrane, germ cell wall, cortex, outer spore membrane, inner coat, outer coat, crust and -in some species- an exosporium. (Abhyankar et al., 2013; McKenney et al., 2013; Setlow, 2014; Thompson and Stewart, 2008).

The most common method used in the food industry to eliminate B. cereus is the application of heat. However, since heat has adverse effects on food quality the food industry is interested in using 
nonthermal technologies such as UV-C (Bintsis et al., 2000; Coohill and Sagripanti, 2009; Gayán et al., 2013; Setlow, 2014). It must be noted that UV-C does not penetrate into foods and as a result its application for food treatment is limited, and it has more potential for treating food contact surfaces (Soni et al., 2016). At a wavelength of $254 \mathrm{~nm}$, UV-C has germicidal and sporicidal properties (Bintsis et al., 2000; Coohill and Sagripanti, 2009; Gayán et al., 2013; Setlow, 2014). The primary target of UVC damage in microbial cells is DNA (Moeller et al., 2014; Setlow, 2014).

Spores are 20-50 times more resistant to UV than their vegetative counterparts (Setlow, 2014). This is due to the fact that spores have: (i) a change in DNA's UV photochemistry due to binding of $\alpha / \beta$ type Small, acid-soluble spore proteins (SASP), (ii) dedicated DNA repair mechanisms, (iii) pigments in the outer layer of some spores. A factor that negatively influences the spore's UV-C resistance is the DPA depot, since spore that lack DPA are more resistant to UV-C (Paidhungat et al., 2000; Setlow, 2006). In vegetative cells, UV-C at a wavelength of $254 \mathrm{~nm}$ generates photoproducts between adjacent pyrimidines in the same DNA strand: 6,4-photoproducts or cyclobutane dimers. These photoproducts are potentially lethal. In contrast, UV radiation of spores generates a thyminylthymine adduct named spore photoproduct (SP). This SP is much less lethal than the photoproduct formed in vegetative cells. The reason why a different photoproduct is formed in spores is that their DNA is saturated with $\alpha / \beta$ SASPs that change the DNA structure from a B-conformation to something between A and B -DNA. This results in a changed DNA photochemistry and a higher resistance to UVC (Mason and Setlow, 1986; Setlow, 2014, 2006).

Directed (laboratory) evolution approaches are becoming increasingly fruitful in food microbiology research to examine the adaptive potential of foodborne pathogens and spoilage organisms (Elena and Lenski, 2003; Gayán et al., 2016; Vanlint et al., 2012; Zeigler and Nicholson, 2017). In contrast to the evolution of vegetative cell properties, the impact of the selection pressure on the evolution and properties of spores has not yet been addressed. In order to investigate the impact of UV-C stress on the evolution of endospore recalcitrance in B. cereus, a directed evolution experiment was set up in 
which B. cereus was repeatedly subjected to sporulation, UV-C treatment, germination and outgrowth. We show here that iterative cycles of UV-C stress on spores of $B$. cereus result in $B$. cereus spores with considerably increased UV-C resistance.

\section{Material \& methods}

\subsection{Strains and spore production}

Stock cultures of ATCC 14579 and resulting controls and clones were stored at $-75^{\circ} \mathrm{C}$ in Brain Heart Infusion (BHI, Oxoid, Basingstoke, England), supplemented with $10 \%$ or $25 \%$ glycerol (Prolabo, Heverlee, Belgium). Working stocks were stored refrigerated at $4{ }^{\circ} \mathrm{C}$ on $\mathrm{BHI}$ agar and were renewed monthly. The sporulation protocol was based on Garcia et al. (Garcia et al., 2010). In short, a single colony was transferred initially into $\mathrm{BHI}$ (Oxoid) and incubated at $30^{\circ} \mathrm{C}$ for 18 to $24 \mathrm{~h} .0 .5 \mathrm{~mL}$ of this overnight culture was transferred into $50 \mathrm{~mL}$ Maltose sporulation medium $\left(1 \mathrm{mM} \mathrm{MgCl} 2.6 \mathrm{H}_{2} \mathrm{O}, 1 \mathrm{mM}\right.$ $\mathrm{Ca}\left(\mathrm{NO}_{3}\right)_{2} .4 \mathrm{H}_{2} \mathrm{O}, 12.5 \mu \mathrm{M} \mathrm{CuCl} 2.2 \mathrm{H}_{2} \mathrm{O}, 12.5 \mu \mathrm{M} \mathrm{ZnCl}, 2.5 \mu \mathrm{M} \mathrm{CoCl} 2.6 \mathrm{H}_{2} \mathrm{O}, 2.5 \mu \mathrm{M} \mathrm{Na}_{2} \mathrm{MoO}_{4} .2 \mathrm{H}_{2} \mathrm{O}$, $5 \mathrm{mM}\left(\mathrm{NH}_{4}\right)_{2} \mathrm{SO}_{4}, 66 \mu \mathrm{M} \mathrm{MnSO}{ }_{4} \cdot \mathrm{H}_{2} \mathrm{O}, 10 \mathrm{mM}$ maltose, $\left.1 \mu \mathrm{M} \mathrm{FeSO}{ }_{4}\right)$ and incubated shaken at $250 \mathrm{RPM}$ for $72 \mathrm{~h}$ (van der Voort et al., 2010). Spores were washed three times with 100mM phosphate buffer supplemented with $0.1 \%$ Tween 80 , incubated for one hour in $50 \%$ ethanol and washed three times with $100 \mathrm{mM}$ phosphate buffer with $0.01 \%$ Tween 80 .

\subsection{Directed evolution of endospores for UV-C resistance}

Five independent batches of spores were produced from five different colonies of a $B$. cereus ATCC 14579 stock plate as a starting point. Three batches of these spores were subjected to five iterative cycles of sporulation, sporicidal UV-C treatment, germination and outgrowth (referred to as stressedlineages; Fig. 1), while two control batches were cycled without stress (producing new generation of spores starting from 100-10,000 spores/mL; referred to as unstressed-lineages; Fig. 1) to determine the effect of repetitive sporulation, germination, and outgrowth. In addition, wild type spores were freshly sporulated at each cycle to check the parental level resistance to corresponding UV-C treatment (referred to as parental control) The lineages were sporulated in maltose sporulation 
medium (see 2.1) for 72 hours and washed, diluted tenfold in $100 \mathrm{mM}$ phosphate buffer with $0.01 \%$ Tween80 and subjected to a UV-C treatment (see 2.3) to obtain a targeted reduction of $2.5 \pm 0.5 \mathrm{log}$ $\mathrm{cfu} / \mathrm{mL}$ reduction. Next, the UV-C treated spores were diluted in Peptone Physiological Solution (PPS) ( $1 \mathrm{~g} / \mathrm{L}$ pepton (Oxiod, Oxford, England) $+8.5 \mathrm{~g} / \mathrm{L} \mathrm{NaCl}$ (Sigma-Aldrich, St. Louis, USA)) with $0.01 \%$ Tween 80 and $3.0 \pm 1.0 \log \mathrm{cfu} / \mathrm{mL}$ was transferred to a new batch of maltose sporulation medium. The unstressed lineages were also washed in $100 \mathrm{mM}$ phosphate buffer with $0.01 \%$ Tween 80 . They were diluted 1000x in PPS before inoculated in fresh MSM medium for outgrowth and sporulation.

\subsection{UV-C treatment of spores and vegetative cells}

During the cycling experiment and the UV-C resistance confirmation experiments, washed spores were $10 x$ diluted upon UV-C treatment in a $100 \mathrm{mM}$ phosphate buffer ( $\mathrm{pH} 7.4)$ supplemented with 0.01\% Tween 80 and $8 \mathrm{~mL}$ was transferred to a Petri dish (55mm, Gosselin Plastics, Borre, France) with a magnetic stir bar. The spores were continuously stirred during the UV-C treatment on a magnetic stirrer (setting 5, RCT basic, IKA, China). UV-C treatment was performed in a closed inox box with a UVpro K17-2 lamp (BioClimatic, The Netherlands). The UV-C dose was increased per cycle starting from $96 \mathrm{~mJ} / \mathrm{cm}^{2}$ to $164 \mathrm{~mJ} / \mathrm{cm}^{2}$. Dosimetry was the average of 3 measurements with an ILT 1700 radiometer connected to XRD140T254 detector (International Light technologies, Peabody, USA). During the cycling experiment, the initial spore concentration of stressed lineages and parental was enumerated after a heat treatment of $70^{\circ} \mathrm{C}$ for 15 minutes to remove vegetative cells or germinated spores. In cycle 5 the intensity of this heat treatment was reduced to $60^{\circ} \mathrm{C}$ for 15 minutes.

For the UV-C inactivation of vegetative cells from UV-C cycled spores, the clones were subcultured twice in $\mathrm{BHI}$ for $24 \mathrm{~h}$ at $30^{\circ} \mathrm{C}$. The vegetative cells were diluted to a target concentration of $3 \mathrm{log}$ $\mathrm{cfu} / \mathrm{mL}$ and incubated during 5 hours at $30^{\circ} \mathrm{C}$ to reach the mid-exponential phase. After 5 hours the samples were diluted 10x in PPS with $0.01 \%$ Tween 80 to a target concentration of 5 log cfu/mL. 
Plastics, Borre, France) with magnetic stir bar. In addition, an extra metal plate was placed inside the UV-C chamber between the UV lamp and the sample to reduce the radiated surface to $1 \mathrm{~cm}^{2}$. After radiation, the samples were diluted in PPS with $0.01 \%$ Tween 80 , then plated on $\mathrm{BHI}$ agar and incubated at $30^{\circ} \mathrm{C}$ for 48 hours. Every dilution series was performed twice and experiments were performed in triplicate. Using the excel tool, Ginafit, a log-linear curve was fitted on the first three time points of the inactivation curve (Geeraerd et al., 2005).

\subsection{Wet heat treatment}

To check for cross-resistance against wet heat stress, $50 \mu \mathrm{L}$ of spores suspensions were transferred to Sterile Ultra-Thin (UTW) walled PCR tubes (0.2mL; BIOplastics, Landgraaf, The Netherlands). Wet heat treatment was done in a PCR cycler (Artktik Thermal cycler - Thermo Scientific, Waltham, USA) with the following settings: $105^{\circ} \mathrm{C}$ lid temperature, sample temperature at $70^{\circ} \mathrm{C}, 15$ minutes of treatment time and then cooling down to $4^{\circ} \mathrm{C}$. At defined time points, samples were taken out and place in an ice bath. Spores were enumerated as explained in 2.5 .

Preliminary experiments showed no difference in spore counts with or without a heat shock of $80^{\circ} \mathrm{C}$ for 10 minutes or $70^{\circ} \mathrm{C}$ for 15 minutes (data not shown). All samples were tenfold diluted in PPS (1 g/L pepton (Oxiod, Oxford, England) $+8.5 \mathrm{~g} / \mathrm{L} \mathrm{NaCl}$ (Sigma-Aldrich, St. Louis, USA)) with $0.01 \%$ Tween 80 and plated on BHI supplemented with $1.5 \%$ agar (Agar Bacteriological, Oxoid, Oxford, England). Surviving spores were counted after 72 hours incubation at $30^{\circ} \mathrm{C}$.

\subsection{Spore count determination with Thoma counting chamber}

Due to germination defects in spores from stressed lineages, actual spore count was determined using phase contrast microscope (Leica, Germany) with Thoma counting chamber (Paul Marienfield, Germany). Three independent spore stocks of wild type and first isolate of stressed lineage A (clone A1, as a representative of stressed lineages) were counted. 
To confirm that no environmental or lab related contamination occurred, PCR and agarose gelelectrophoresis were performed on isolates at certain time points during the cycling experiment to confirm that the spores were all descendants from the parental ATCC 14579 strain. The first primer pair (BCM_BC5267F1 and BcM_BC5267R1) is specific for B. cereus sensu stricto strain ATCC 14579 and targets the BC5267 gene. The wild type (parental) and all the cycled lineages (including UV-C treated and non- UV-C treated lineages)should test positive for this primer pair. In addition, two other primer pairs were included in this quality control. The target genes of these primer pairs are not present in ATCC 14759 and as a results the PCR results should be negative for all lineages. DNA was extracted from vegetative cells by heating the samples in a lysis buffer ( $10 \%$ sodium dodecylsulfate, $1 \mathrm{~N} \mathrm{NaOH}$ ). PCR was performed with the Q5 ${ }^{\mathrm{TM}}$ High-Fidelity 2X Master Mix (New England Biolabs inc, Massachusetts, USA) and the following primers were used: BcM_BC5267F1 5'CCAAAGAGTTAAGGGCTGTTAG-3', BcM_BC5267R1: 5'-GTTGAAGGGTTCTTACCAAGATG-3', BcT_cytK1_F: 5'-TACCAGTTCCGAATGTAAAGC-3', BcT_cytK1_R: 5'-GCTTAGTCATCGCTGGTG-3', BcP_cspA_F: 5'-TCGAAGTTCCAGGCGAAAAC-3' and BcP_cspA_R: 5'-CTGTTCTTCACGAAGCCTTTTC-3'. Only the primers BcM_BC5267F1 and BcM_BC5267R1 are specific for the parental strain and show a band at 680 bp on gel (data not shown).

\subsection{Germination assays}

Spores of the UV resistant and control clones were germinated in an assay containing a high and a low concentration of the germinant L-alanine (Acros Organics, Geel) (Broussolle et al., 2008).

The spores were centrifuged at $10000 \times \mathrm{G}$ for 15 minutes at $4^{\circ} \mathrm{C}$ and suspended in a germination buffer of 10mM Tris/HCl (Trizma base (Sigma-Aldrich, St. Louis, USA) + HCl (Sigma-Aldrich, St. Louis, USA)) (pH = 7,4) and 20mM D-cycloserine (Sigma-Aldrich, St. Louis, USA) supplemented with $0.01 \%$ Tween 80 after the supernatant was removed. D-cycloserine was added to prevent the alanine racemase activity of spores (Broussolle et al., 2008). 
Germination was monitored by measuring the optical density decrease at $600 \mathrm{~nm}$ in a Versamax microplate reader (Molecular Devices, San Jose, USA) during six hours incubation at $30^{\circ} \mathrm{C}$. The $\mathrm{OD}_{600}$ was read every 2 minutes after firmly shaking the microplate to prevent settling of spores. The percentage of the $O D_{600}$ decrease was calculated using following formula: $\left[1-\left\{O D_{t}-\left(O D_{c t}-O D_{c 0}\right)\right\} /\right.$ $\left.O D_{0}\right] \times 100$, where $O D_{t}$ and $O D_{c t}$ are the $O D_{600}$ values for respectively the test sample and negative control (buffer without L-alanine, but with spores) measured after time $t$, and where $\mathrm{OD}_{0}$ and $\mathrm{OD}_{\mathrm{co}}$ are the initial $\mathrm{OD}_{600}$ values for respectively the test sample and negative control. This percentage expressed the extent of germination (Broussolle et al., 2008).

\subsection{Time-lapse phase contrast microscopy (TLM)}

To quantify different subpopulations in spore stocks and germinating spores among them, time-lapse phase contrast microscopy analysis was performed with an Eclipse Ti-E inverted microscope (Nikon Instruments Europe BV, Netherlands) equipped with a microscope incubator (Okolab, Italy) and a TICT-E motorized condenser. Images were acquired by CoolSnap HQ2 FireWire CCD camera using NIS Element (Nikon), and were further handled with open source software FIJI (Schindelin et al., 2012). For Imaging of $B$. cereus spores and their germination, spores were placed between agarose pads and a cover glass using Gene Frames (Thermo Fischer Scientific, USA). However, the germination response of $B$. cereus spores to nutrients is very rapid, and spores already turn phase dark during the preparations of agarose pad and microscopy. To overcome this issue, a nutrient diffusion time-lapse microscopy technique was applied. In short, a $4 \mathrm{X} \mathrm{BHI}+1.5 \%$ agarose pad is positioned next to a pure agarose pad (1.5\% agarose in sterile miliQ water) on a glass slide and it is pushed towards the pure agarose pad to make contact just before placing the slide on the microscope platform, so that nutrients start diffusing into the pure agarose pad. In this way, the germination response can be delayed enough to capture the initial state of the spores in the middle part of the pure agarose pad. More than 2,000 spores were counted from each spore stock of three independent spore productions of wild type and the first isolate from stressed lineage $A$. 
All microbial resistance determinations were performed at least 3 times on different working days.

200

201

202 Statistical analyses, boxplots to detect outliers, t-test $(p=0.05)$, and ANOVA tests $(p=0.05)$ were carried out using the SPSS software version 25 (IBM SPSS Statistics for Windows, New York, USA), and differences were considered significant when $p \leq 0.05$.

\section{Results}

\subsection{Directed evolution for UV-C resistance}

The results of the directed evolution with UV-C on B. cereus (ATCC 14759) endospores are displayed in figure 2. The UV-C dose varied from cycle to cycle. For the first cycle the UV-C dose was $96 \mathrm{~mJ} / \mathrm{cm}^{2}$, to ensure the targeted 2-3 log cfu endospores $/ \mathrm{mL}$ reduction this was increased to $107 \mathrm{~mJ} / \mathrm{cm}^{2}$ for the next 3 cycles and finally a UV-C dose of $164 \mathrm{~mJ} / \mathrm{cm}^{2}$ was applied in the last cycle. After four cycles, two out of three UV-C stressed lineages showed remarkable increase in UV-C resistance. The fifth and last cycle had an increased dosage of $164 \mathrm{~mJ} / \mathrm{cm}^{2}$ and at these dosage all three lineages showed no endospore reduction, while the parental control showed ca. $4 \log \mathrm{cfu} / \mathrm{mL}$ reduction. These results demonstrate that directed evolution can significantly increase the UV-C resistance of $B$. cereus endospores. All lineages are confirmed as descendants from ATCC 14759 with PCR and gelelectrophoresis (data not shown). To determine that only spores were counted, the aliquot used to count the spores before UV-C treatment received a heat shock of $70^{\circ} \mathrm{C}$ for 15 minutes to eliminate vegetative cells or germinated spores. In cycle 5 the initial spore counts before UV-C treatment decreased, even to lower numbers than the counts after UV-C treatment (panel B, Fig. 2). This implicates a possible inactivation during the heat treatment step and a milder heat treatment at $60^{\circ} \mathrm{C}$ for 15 minutes yielded a higher initial spore count. This rules out the possibility of vegetative cells being responsible for this increase and it was the first hint linking UV-C resistance to wet heat sensitivity. 
Per lineage, three random clones were purified and UV-C resistance of the corresponding spore crops was confirmed with a dosage of $164 \mathrm{~mJ} / \mathrm{cm}^{2}$ (Fig. 3). All stress-cycled isolates, with the exception of isolate two in lineage three, were confirmed to have significantly increased UV-C resistance $(p<0.05)$ compared to the parental control. Non-stressed cycled lineages did not acquire significant UV-C resistance, indicating that cycling alone does not select for this phenotype. On average all UV cycled isolates had a reduction of $1.1 \pm 0.8 \log \mathrm{cfu} / \mathrm{mL}$, compared to $3.1 \pm 0.6 \log \mathrm{cfu} / \mathrm{mL}$ reduction for wild type and non-stress cycled isolates. More in detail, the average reduction for isolate A1 is $0.9 \pm 0.4$ $\log \mathrm{cfu} / \mathrm{mL}$, isolate $\mathrm{A} 20.6 \pm 0.4 \log \mathrm{cfu} / \mathrm{mL}$, isolate A3 $0.8 \pm 0.6 \log \mathrm{cfu} / \mathrm{mL}$, isolate B1 $0.8 \pm 0.6 \log$ $\mathrm{cfu} / \mathrm{mL}$, isolate B2 $0.8 \pm 0.9 \log \mathrm{cfu} / \mathrm{mL}$, isolate B3 $1.0 \pm 0.5 \log \mathrm{cfu} / \mathrm{mL}$, isolate $\mathrm{C} 11.3 \pm 0.8 \log \mathrm{cfu} / \mathrm{mL}$, isolate C2 $2.2 \pm 1.1 \log \mathrm{cfu} / \mathrm{mL}$ and isolate C3 $1.2 \pm 0.6 \log \mathrm{cfu} / \mathrm{mL}$.

\subsection{Heat resistance of UV-C resistant clones}

To examine to what extent acquisition of UV-C resistance could coincide with cross-resistance to other stresses such as heat, spore crops of clones $\mathrm{A} 1, \mathrm{~B} 1, \mathrm{C} 1, \mathrm{X} 1$ and $\mathrm{Y} 1$ where tested against wet heat inactivation at $70^{\circ} \mathrm{C}$ (Fig. 4). Surprisingly, UV-C resistant clones proved to be heat sensitive, and displayed viability reduction within the first minute of respectively $1.1 \pm 0.3,1.2 \pm 0.2$ and $1.4 \pm 0.1$ $\log \mathrm{CFU} / \mathrm{mL}$ for clone $\mathrm{A} 1, \mathrm{~B} 1$ and $\mathrm{C} 1$. The non-stress cycled (X1 and $\mathrm{Y} 1)$ and parental control showed no significant reduction. After the decrease in the first minute a tail is visible with a reduction over the next 14 minutes of respectively $0.7 \pm 0.2,0.6 \pm 0.2$ and $0.3 \pm 0.2 \log \mathrm{CFU} / \mathrm{mL}$ for isolate $A 1, \mathrm{~B} 1$ and C1. These results indicate that there is a subpopulation sensitive to wet heat, possibly as a trade-off for UV-C resistance.

\subsection{Germination defect in UV-C resistant clones}

From preliminary phase contrast microscopy, the total number of spores of UV-C resistant clones in microscopic fields was similar to that of the wild type. However, the clones showed decreased cfu on BHI plate count of $8.5 \pm 0.2 \log \mathrm{CFU} / \mathrm{ml}$, while the wild type showed $9.8 \pm 0.1 \log \mathrm{CFU} / \mathrm{ml}$ (Table 1$)$. A germination assay employing optical density (OD) at $600 \mathrm{~nm}$ proved that the addition of the 
germinant L-alanine, either in high or in low concentration, did not result in a noticeable OD drop for spore crops of the UV-C resistant clones (Fig. 5). In contrast, the parental control and non-stressed cycled controls (clone $\mathrm{X} 1$ and $\mathrm{Y} 1$ ) did display an OD decrease. For the parental control the OD decrease one hour after the addition of $100 \mathrm{mM}$ L-alanine was $26.0 \%$ compared to $7.8 \%$ for $10 \mathrm{mM}$ L-alanine. For non-stress cycled controls ( $\mathrm{X} 1$ and $\mathrm{Y} 1$ ) and the parental control the mean percentage of OD decrease was respectively 51, 52 and $51 \%$ after four hours of incubation in $10 \mathrm{mM}$ L-alanine and respectively 56,55 and $56 \%$ after four hours of incubation in $100 \mathrm{mM} \mathrm{L-alanine.} \mathrm{These} \mathrm{results}$ indicate that a substantial germination defect exists in spores of the UV-C resistant clones.

To determine the accurate spore concentrations, a Thoma counting chamber was used (Table 1) for three independent spore stocks of the wild type ATCC 14579 and clone A1. As all independently evolved lineages showed similar phenotypes, the clone A1 was used in further analyses as a representative of UV-C resistant clones. As seen in Table 1, actual spore concentration of A1 from Thoma counting chamber was comparable to the wild type. The lower plate count of clone A1 compared to the wild type can be explained by a lower germination frequency. Time-lapse phase contrast microscopy was also performed to see how many spores actually responded to nutrientinduced germination by $\mathrm{BHI}$ medium. Using both the plate count/Thoma counting chamber ratio and time-lapse microscopy observations, it was estimated that approximately only $5 \%$ of the spores germinated in the A1 clone (Table 1).

Another distinctive difference between the wild type and the obtained UV-C resistant clones is spore morphology (Fig. 6, lower panel). Indeed, the refractility within UV-C resistant spore crops was more heterogeneous compared to the parental spore population. It is important to highlight here that the heterogeneity in refractility has an important impact on the results in the OD germination assay (Fig. 5). The bulk OD measurements of Fig. 5 would not be able detect possible germination events stemming from the already phase-dark spores. However, a much more detailed subsequent TLM analysis clearly confirms the overall germination defect, and furthermore indicates that the group of 
phase-dark/grey spores displays very low germination efficiency (Fig. 6).A substantial amount of phase dark and grey spores was also found in spore stocks of A1 clone while over $95 \%$ of spores were phase bright in the wild type (Fig. 6, top panel). Figure 6 shows which type of spores were germinated under TLM. Small fractions of phase dark and grey spores in A1 were able to germinate while only phase bright spores were germinated in the wild type. This might indicate that the phase dark spores in A1 are different from those of the wild type in terms of viability.

\subsection{UV-C inactivation of vegetative cells of UV-C cycled spores}

As discussed previously in 3.1, spores of all three UV-C cycled lineages and corresponding spore crops of clones A1, B1 and C1 showed an increased resistance against UV-C, compared to the wild type. To verify if this increased resistance also affects the UV-C resistance of their vegetative counterparts, triplicate experiments were performed to assess the UV-C inactivation of the corresponding vegetative cells in liquid. The vegetative cells displayed a two-phase inactivation curve and there were no differences found in inactivation between A1, B1, C1 clones and the wild type (Fig.7). Loglinear inactivation curves, using the first three time points, were fitted using GInafit. The inactivation rate $\left(K_{\max }\right) \pm \mathrm{SE}$ is $1.46 \pm 0.28$ for $\mathrm{A} 1,1.24 \pm 0.18$ for $\mathrm{B} 1,1.54 \pm 0.19$ for $\mathrm{C} 1$ and $1.54 \pm 0.25$ for the wild type. Our results show that although the UV-C cycled spores are more resistant to UV-C, this trait is not present in their vegetative stage.

\section{Discussion}

Directed evolution experiments with UV-C inactivation help to understand the mechanisms and evolvability of endospore recalcitrance. While directed evolution experiments with UV-C stress on vegetative cells have been reported in literature, this is to the best of our knowledge the first directed evolution approach on UV-C resistance on bacterial endospores. We show here that repeated exposure of $B$. cereus endospores to UV-C stress reproducibly results in the selection of mutants yielding spores with an increased UV-C resistance ( $\geq 30$ fold compared to the wild type at $\left.164 \mathrm{~mJ} / \mathrm{cm}^{2}\right)$. 
B. cereus does not only have the ability to spoil food, it can also produce toxins and cause illness. In

298 the food industry, UV is applied to disinfect (food) contact surfaces, water and air (Bintsis et al., 2000). Taken into account the relatively short time it took to get UV-C resistance, an in-house microbiota of $B$. cereus spores could potentially get increased resistance towards the UV-C disinfection techniques used. We show here that three independent lineages acquired UV-C resistance. However, this resistance is accompanied by compromised heat resistance and germination deficiencies and this will lower the overall survival capacities of these spores in food processing. Another application for this research is in the biopesticides industry. $B$. thuringiensis has been used for many years as a biopesticide. Multiple research focusses on increasing the resistance of $B$. thuringiensis to UV and thus prolonging the persistence on the field (Saxena et al., 2002; Zhang et al., 2018, 2016).

Interestingly, it seems that all three independently evolved lineages display similar phenotypes in which an increased UV-C resistance was inevitably accompanied by a decreased wet heat resistance and germination efficiency. With regard to the reduced germination efficiency, microscopic analysis indicates that UV-C resistant spore crops display an increased fraction of phase dark and grey spores. However, this increased fraction cannot solely be responsible for the wet heat sensitivity as the reduction found after wet heat treatment was bigger than the fraction phase-dark and phase-grey spores. It was recently suggested for B. subtilis that defects in spore coat assembly or core dehydration during late sporulation stage may lead to premature germination triggered by GerA, eventually yielding phase dark or grey spores (Ramírez-Guadiana et al., 2017). In addition, the lipoproteins, YlaJ and YhcN have been shown to contribute to the efficiency of spore germination in B. subtilis (Johnson and Moir, 2017). It is known that low DPA levels increases the resistance of spores to UV-C, increases core water activity and sensitizes spores to wet heat stress. Notably, spores with low DPA levels tent to germinate spontaneously (Paidhungat et al., 2000). However, since UV-C resistance, heat resistance and germination are supported by complex multifactorial processes (Setlow, 2014, 2006), their interrelationship will be further addressed in the future. 
323 The UV-C resistance of the vegetative cells was not affected by our evolution. This is in agreement

324 with the fact that the damage inflicted by UV-C is different between spores and vegetative cells. UV

325 radiation of spores produces the thyminyl-thymine adduct that is named spore photoproduct (SP)

326 and that is much less lethal than the pyrimidine dimers formed in vegetative cells (Setlow, 2014).

327 This work provides useful insights in endospore evolution and its impact on the surviving $B$. cereus

328 spores. Directed evolution of $B$. cereus spores by UV-C could drive several independent lineages

329 within a relatively short time to acquire increased UV-C spore resistance while trading off wet heat

330 resistance and germination efficiency.

331 5. Acknowledgements

332 This research is supported by grants from the Research Foundation of Flanders (FWO-Vlaanderen;

333 GOB5616N), and the KU Leuven Research Fund (DBOF/14/049). We would like to thank all non-

334 author lab members and students, who have helped with the experimental work. 


\section{References}

Abhyankar, W., Hossain, A.H., Djajasaputra, A., Permpoonpattana, P., Ter Beek, A., Dekker, H.L., Cutting, S.M., Brul, S., de Koning, L.J., de Koster, C.G., 2013. In pursuit of protein targets: proteomic characterization of bacterial spore outer layers. J. Proteome Res. 12, 4507-4521. https://doi.org/10.1021/pr4005629

Bintsis, T., Litopoulou-Tzanetaki, E., Robinson, R.K., 2000. Existing and potential applications of ultraviolet light in the food industry - A critical review. J. Sci. Food Agric. 80, 637-645. https://doi.org/10.1002/(SICI)1097-0010(20000501)80:6<637::AID-JSFA603>3.0.CO;2-1

Broussolle, V., Gauillard, F., Nguyen-The, C., Carlin, F., 2008. Diversity of spore germination in response to inosine and $\mathrm{L}$-alanine and its interaction with $\mathrm{NaCl}$ and $\mathrm{pH}$ in the Bacillus cereus group. J. Appl. Microbiol. 105, 1081-1090. https://doi.org/10.1111/j.1365-2672.2008.03847.x

Carlin, F., 2011. Origin of bacterial spores contaminating foods. Food Microbiol. 28, 177-182. https://doi.org/10.1016/j.fm.2010.07.008

Coohill, T.P., Sagripanti, J.L., 2009. Bacterial inactivation by solar ultraviolet radiation compared with sensitivity to $254 \mathrm{~nm}$ radiation. Photochem. Photobiol. 85, 1043-1052. https://doi.org/10.1111/j.1751-1097.2009.00586.x

Eijlander, R.T., Abee, T., Kuipers, O.P., 2011. Bacterial spores in food: How phenotypic variability complicates prediction of spore properties and bacterial behavior. Curr. Opin. Biotechnol. 22, 180-186. https://doi.org/10.1016/j.copbio.2010.11.009

Elena, S.F., Lenski, R.E., 2003. Evolution experiments with microorganisms: The dynamics and genetic bases of adaptation. Nat. Rev. Genet. 4, 457-469. https://doi.org/10.1038/nrg1088

Fagerlund, A., Lindbäck, T., Storset, A.K., Granum, P.E., Hardy, S.P., 2008. Bacillus cereus Nhe is a pore-forming toxin with structural and functional properties similar to the ClyA (HlyE, SheA) 
family of haemolysins, able to induce osmotic lysis in epithelia. Microbiology 154, 1554.

https://doi.org/10.1099/mic.0.2007/014134-0

Ganash, M., Phung, D., Sedelnikova, S.E., Lindbäck, T., Granum, P.E., Artymiuk, P.J., 2013. Structure of the NheA component of the Nhe toxin from Bacillus cereus: implications for function. PLoS One 8, e74748. https://doi.org/10.1371/journal.pone.0074748

Garcia, D., der Voort, M. van, Abee, T., 2010. Comparative analysis of Bacillus weihenstephanensis KBAB4 spores obtained at different temperatures. Int. J. Food Microbiol. 140, 146-153. https://doi.org/10.1016/j.ijfoodmicro.2010.04.005

Gayán, E., Álvarez, I., Condón, S., 2013. Inactivation of bacterial spores by UV-C light. Innov. Food Sci. Emerg. Technol. 19, 140-145. https://doi.org/10.1016/j.ifset.2013.04.007

Gayán, E., Cambré, A., Michiels, C.W., Aertsen, A., 2016. Stress-induced evolution of heat resistance and resuscitation speed in Escherichia coli 0157:H7 ATCC 43888. Appl. Environ. Microbiol. 82, 6656-6663. https://doi.org/10.1128/AEM.02027-16

Geeraerd, A.H., Valdramidis, V.P., Van Impe, J.F., 2005. GInaFiT, a freeware tool to assess non-loglinear microbial survivor curves. Int. J. Food Microbiol. 102, 95-105. https://doi.org/10.1016/J.IJFOODMICRO.2004.11.038

Heyndrickx, M., 2011. The importance of endospore-forming bacteria originating from soil for contamination of industrial food processing. Appl. Environ. Soil Sci. 1-11. https://doi.org/10.1155/2011/561975

Hindle, A.A., Hall, E.A.H., 1999. Dipicolinic acid (DPA) assay revisited and appraised for spore detection. Analyst 124, 1599-1604. https://doi.org/10.1039/a906846e

Johnson, C.L., Moir, A., 2017. Proteins YlaJ and YhcN contribute to the efficiency of spore germination in Bacillus subtilis. FEMS Microbiol. Lett. 364. https://doi.org/10.1093/femsle/fnx047 
Lund, T., De Buyser, M.L., Granum, P.E., 2000. A new cytotoxin from Bacillus cereus that may cause necrotic enteritis. Mol. Microbiol. 38, 254-261. https://doi.org/10.1046/j.13652958.2000.02147.x

Mason, J.M., Setlow, P., 1986. Essential role of small, acid-soluble spore proteins in resistance of Bacillus subtilis spores to UV Light. J. Bacteriol. 167, 174-178.

McKenney, P.T., Driks, A., Eichenberger, P., 2013. The Bacillus subtilis endospore: assembly and functions of the multilayered coat. Nat. Rev. Microbiol. 11, 33-44. https://doi.org/10.1038/nrmicro2921

Moeller, R., Raguse, M., Reitz, G., Okayasu, R., Li, Z., Klein, S., Setlow, P., Nicholson, W.L., 2014. Resistance of Bacillus subtilis spore DNA to lethal ionizing radiation damage relies primarily on spore core components and DNA repair, with minor effects of oxygen radical detoxification. Appl. Environ. Microbiol. 80, 104-109. https://doi.org/10.1128/AEM.03136-13

Nicholson, W.L., Munakata, N., Horneck, G., Melosh, H.J., Setlow, P., 2000. Resistance of Bacillus endospores to extreme terrestrial and extraterrestrial environments. Microbiol. Mol. Biol. Rev. $64,548-72$.

Paidhungat, M, Setlow, B., Driks, A., Setlow, P., 2000. Characterization of spores of Bacillus subtilis which lack dipicolinic acid. J. Bacteriol. 182, 5505-12.

Ramírez-Guadiana, F.H., Meeske, A.J., Wang, X., Rodrigues, C.D.A., Rudner, D.Z., 2017. The Bacillus subtilis germinant receptor GerA triggers premature germination in response to morphological defects during sporulation. Mol. Microbiol. 105, 689-704. https://doi.org/10.1111/mmi.13728

Saxena, D., Ben-Dov, E., Manasherob, R., Barak, Z., Boussiba, S., Zaritsky, A., 2002. A UV tolerant mutant of Bacillus thuringiensis subsp. kurstaki producing melanin. Curr. Microbiol. 44, 25-30.

Schindelin, J., Arganda-Carreras, I., Frise, E., Kaynig, V., Longair, M., Pietzsch, T., Preibisch, S., Rueden, C., Saalfeld, S., Schmid, B., Tinevez, J.-Y., White, D.J., Hartenstein, V., Eliceiri, K., Tomancak, P., 
Cardona, A., 2012. Fiji: an open-source platform for biological-image analysis. Nat. Methods 9 , 676-682. https://doi.org/10.1038/nmeth.2019

Setlow, P., 2014. Spore resistance properties. Microbiol. Spectr. 2, TBS-0003-2012. https://doi.org/10.1128/microbiolspec

Setlow, P., 2006. Spores of Bacillus subtilis: their resistance to and killing by radiation, heat and chemicals. J. Appl. Microbiol. 101, 514-525. https://doi.org/10.1111/j.1365-2672.2005.02736.x

Soni, A., Oey, I., Silcock, P., Bremer, P., 2016. Bacillus spores in the food industry: a review on resistance and response to novel inactivation technologies. Compr. Rev. Food Sci. Food Saf. 15, 1139-1148. https://doi.org/10.1111/1541-4337.12231

Stenfors Arnesen, L.P., Fagerlund, A., Granum, P.E., 2008. From soil to gut: Bacillus cereus and its food poisoning toxins. FEMS Microbiol. Rev. 32, 579-606. https://doi.org/10.1111/j.1574$6976.2008 .00112 \cdot x$

Thompson, B.M., Stewart, G.C., 2008. Targeting of the BclA and BclB proteins to the Bacillus anthracis spore surface. Mol. Microbiol. 70, 421-434. https://doi.org/10.1111/j.1365-2958.2008.06420.x

van der Voort, M., García, D., Moezelaar, R., Abee, T., 2010. Germinant receptor diversity and germination responses of four strains of the Bacillus cereus group. Int. J. Food Microbiol. 139, 108-115. https://doi.org/10.1016/J.IJFOODMICRO.2010.01.028

Vanlint, D., Rutten, N., Michiels, C.W., Aertsen, A., 2012. Emergence and stability of high-pressure resistance in different food-borne pathogens. Appl. Environ. Microbiol. 78, 3234-3241. https://doi.org/10.1128/AEM.00030-12

Warda, A.K., den Besten, H.M.W., Sha, N., Abee, T., Nierop Groot, M.N., 2015. Influence of food matrix on outgrowth heterogeneity of heat damaged Bacillus cereus spores. Int. J. Food Microbiol. 201, 27-34. https://doi.org/10.1016/j.ijfoodmicro.2015.02.010 
Wassmann, M., Moeller, R., Rabbow, E., Panitz, C., Horneck, G., Reitz, G., Douki, T., Cadet, J., StanLotter, H., Cockell, C.S., Rettberg, P., 2012. Survival of spores of the UV-resistant Bacillus subtilis Strain MW01 after exposure to low-earth orbit and simulated martian conditions: data from the space experiment ADAPT on EXPOSE-E. Astrobiology 12, 498-507. https://doi.org/10.1089/ast.2011.0772

Wassmann, M., Moeller, R., Reitz, G., Rettberg, P., 2010. Adaptation of Bacillus subtilis cells to archean-like UV climate: relevant hints of microbial evolution to remarkably increased radiation resistance. Astrobiology 10, 605-615. https://doi.org/10.1089/ast.2009.0455

Wells-Bennik, M.H.J., Eijlander, R.T., den Besten, H.M.W., Berendsen, E.M., Warda, A.K., Krawczyk, A.O., Nierop Groot, M.N., Xiao, Y., Zwietering, M.H., Kuipers, O.P., Abee, T., 2016. Bacterial spores in food: survival, emergence, and outgrowth. Annu. Rev. Food Sci. Technol. 7, 457-482. https://doi.org/10.1146/annurev-food-041715-033144

Zeigler, D.R., Nicholson, W.L., 2017. Experimental evolution of Bacillus subtilis. Environ. Microbiol. 19, 3415-3422. https://doi.org/10.1111/1462-2920.13831

Zhang, L., Zhang, X., Batool, K., Hu, X., Chen, M., Xu, J., Wang, J., Pan, X., Huang, T., Xu, L., Yu, X.Q., Guan, X., 2018. Comparison and mechanism of the UV-Resistant mosquitocidal Bt mutant LLP29-M19. J. Med. Entomol. https://doi.org/10.1093/jme/tjx192

Zhang, L., Zhang, X., Zhang, Y., Wu, S., Gelbič, I., Xu, L., Guan, X., 2016. A new formulation of Bacillus thuringiensis: UV protection and sustained release mosquito larvae studies. Sci. Rep. 6, 39425. https://doi.org/10.1038/srep39425 
Tables

Table 1. Spore concentration and germination rate of the wild type and UV resistant clone A1.

Spore concentration

$(\log \mathrm{CFU} / \mathrm{ml})$

\section{\% Germination}

Thoma chamber

\begin{tabular}{ccccc} 
& Thoma chamber & Plate count & Plate/Thoma & TLM* \\
\hline WT & $9.8 \pm 0.1$ & $9.8 \pm 0.1$ & $94.5 \pm 15.6 \%$ & $94.5 \pm 0.8 \%$ \\
A1** & $9.8 \pm 0.1$ & $8.5 \pm 0.2$ & $5.4 \pm 2.8 \%$ & $4.9 \pm 1.0 \%$ \\
\hline
\end{tabular}

Plate/Thoma

TLM*

TLM*: Data from nutrient diffusion time-lapse phase contrast microscopy.

A $1^{* *}$ : Isolate $A$ from stressed lineage 1 as a representative of resistant mutants. 
Figure captions

Figure 1. Set-up of cycling experiment. Three lineages were started independently from each other from a single colony of Bacillus cereus ATCC 14579. Each lineage (lineage A, B, and C) underwent subsequent cycles of sporulation, UV-C treatment to target 2-3 log cfu/mL reduction, germination and growth. Two types of controls were conducted: (i) two control lineages cycled without stress (unstressed lineages, lines $X$ and $Y$ ) and (ii) one control wild type spore stock of ATCC 14579 freshly sporulated at each cycle to check initial UV-C resistance level of ancestral population.

Figure 2. Results of directed evolution with UV-C stress on B. cereus endospores. (A) Three independent lineages were cycled for UV-C stress (lineage A, B and C). UV-C reduction in log $N / N_{0}$ are displayed. For $\log \mathrm{N}_{0}$ (spore counts prior to UV-C treatment, in $\log \mathrm{cfu} / \mathrm{mL}$ ) the spore solution received a heat shock of $70^{\circ} \mathrm{C}$ for 15 minutes before plating. UV-C dosage is displayed on top of the graph. (B) Detailed overview of the spore concentrations $\left(\log N_{0}\right)$ in cycle 5 of the directed evolution experiment. Spore were counted after no heat treatment, $70^{\circ} \mathrm{C}$ for 15 minutes or $60^{\circ} \mathrm{C}$ for 15 minutes.

Figure 3. Confirmation of UV-C resistance of clones isolated from the cycling experiment. Three clones were isolated per lineage. All UV-C resistant isolates - except isolate 2 of lineage C- are significantly more resistant to UV-C at a dose op $164 \mathrm{~mJ} / \mathrm{cm}^{2}$ compare to the wild type. ${ }^{*}$ Indicates significant difference $(p<0,05)$ compared to control group evolved without UV treatment and wild type.

Figure 4. Heat resistance of selected UV-C clones at $70^{\circ} \mathrm{C}$. UV- resistant isolate $\mathrm{A} 1$, isolate $\mathrm{B} 1$ and isolate $\mathrm{C} 1$ was compared to the non-stress controls (isolate $\mathrm{X} 1$ and isolate $\mathrm{Y} 1$ ) and the wild type at $70^{\circ} \mathrm{C}$ for 15 minutes. Mean plate counts of 5 replicates are displayed. Out of five replicates per isolate extreme outlier were detected with boxplots and removed from the statistical analysis.

Figure 5. Germination assays with L-alanine. Mean percentages of optical density drop at $600 \mathrm{~nm}$ of clone A1 $(\mathbf{\Delta})$, clone B1 $(\bullet)$ and clone $\mathrm{C} 1(\bullet)$ and control X1 $(\Delta)$, control Y1 $(\bullet)$ and wild type $(\diamond)$ 
with (A) $10 \mathrm{mM}$ and (B) $100 \mathrm{mM} \mathrm{L-alanine} \mathrm{in} \mathrm{function} \mathrm{of} \mathrm{time.} \mathrm{Means} \mathrm{of} \mathrm{four} \mathrm{biological} \mathrm{replicates} \mathrm{and}$ standard deviation are displayed.

Figure 6. Germination time-lapse microscopy results in detail. Left side panel is the wild type and A1 is on the right. Top panel: total number of analyzed spores and a representative image of the spore crop. Middle: subpopulation composition based on relative refractility and the number of spores in each category. Bottom: germination efficiency and the number of germinated spores in each category.

Figure 7. UV-C inactivation of vegetative cells of UV-C cycled spores and the wild type. Three biological replicate were performed and mean plate counts are displayed. 
Figure 1

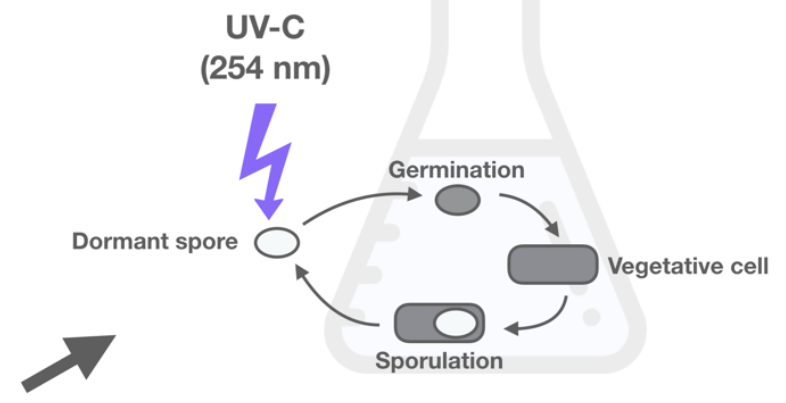

\section{Stressed lineages}

(Directed evolution)

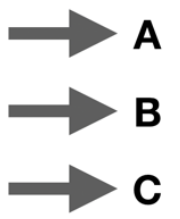

B. cereus

ATCC 14579

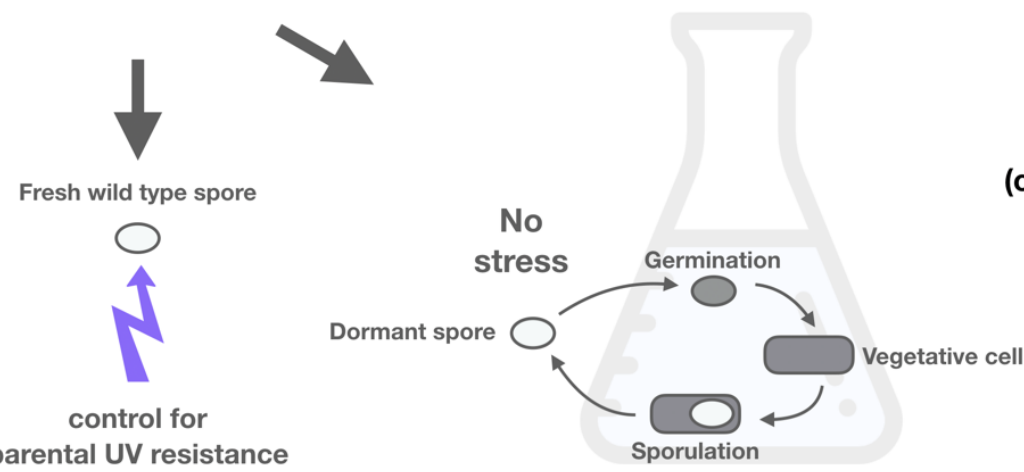

Unstressed lineages

(control for spontaneous mutation)

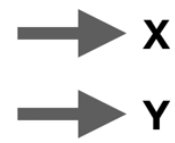

parental UV resistance 
Figure 2

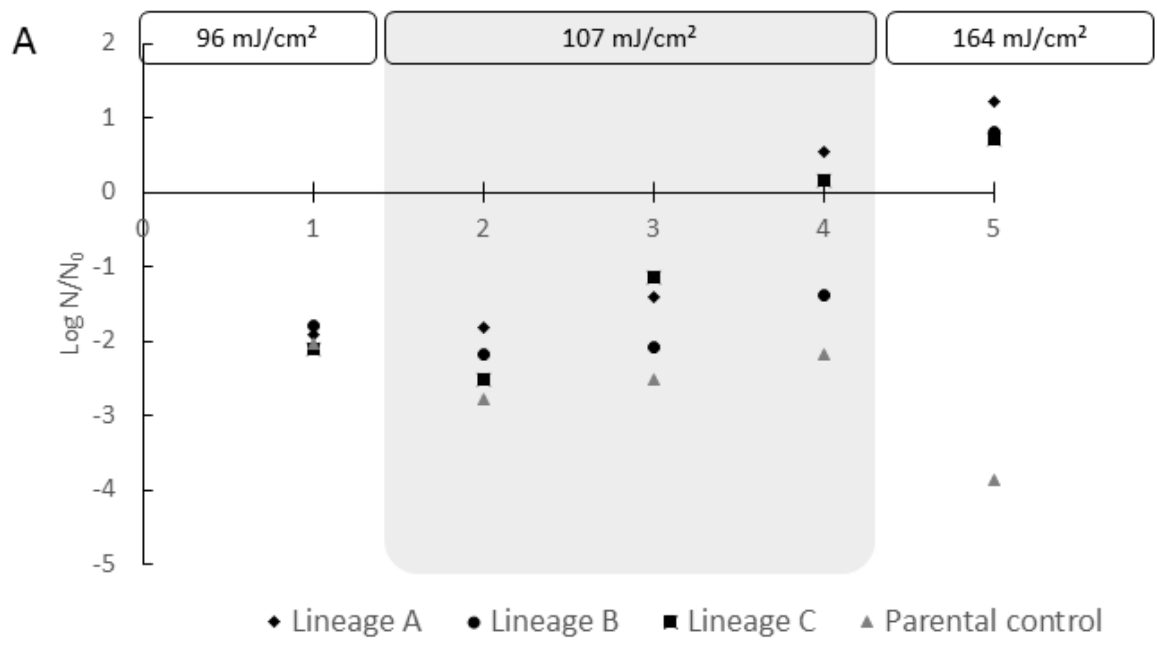

B

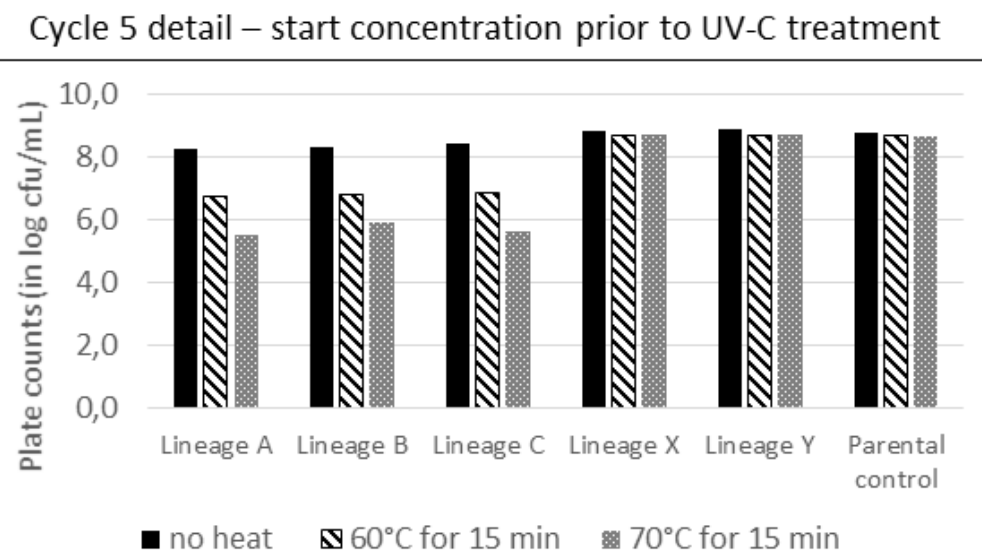


Figure 3

5

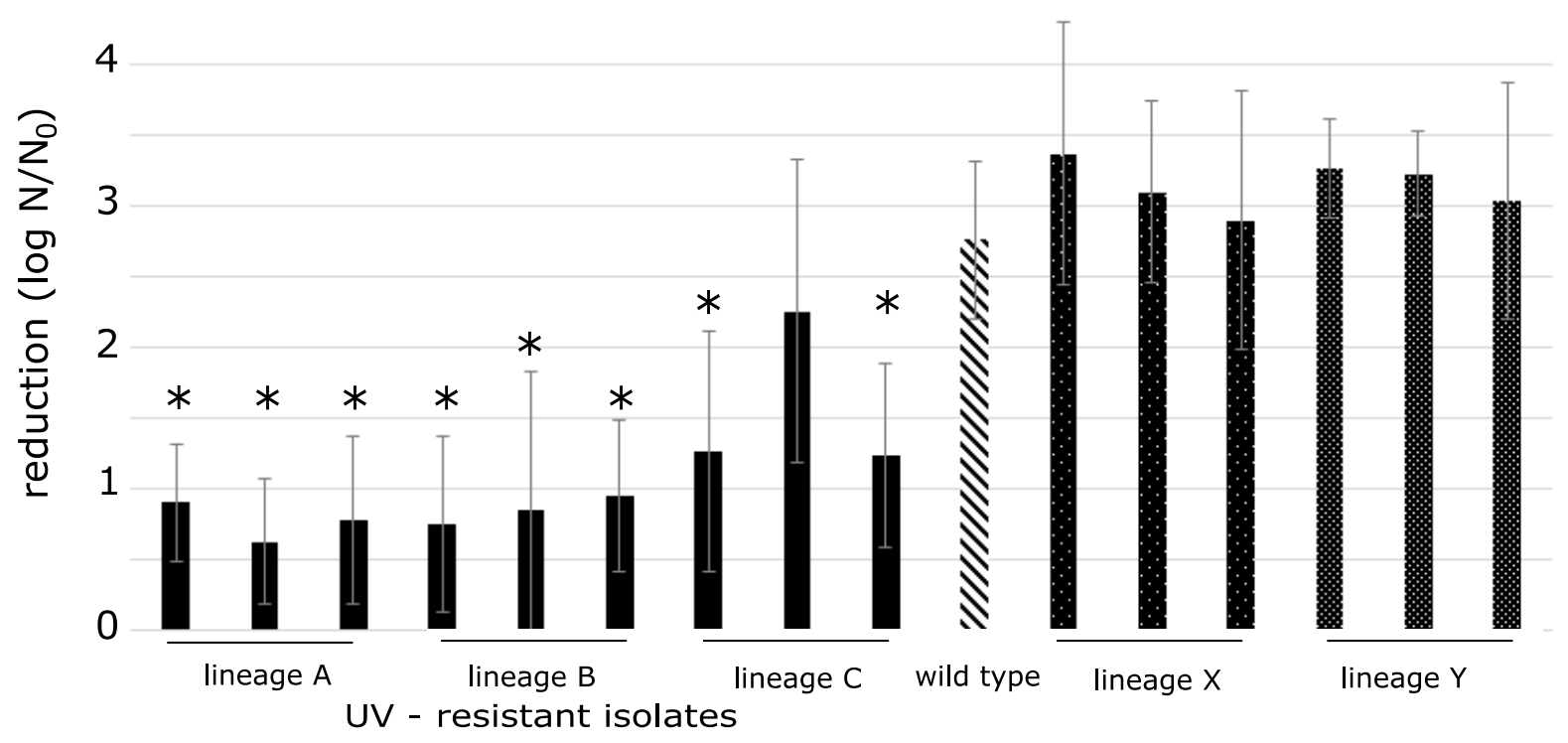


Figure 4

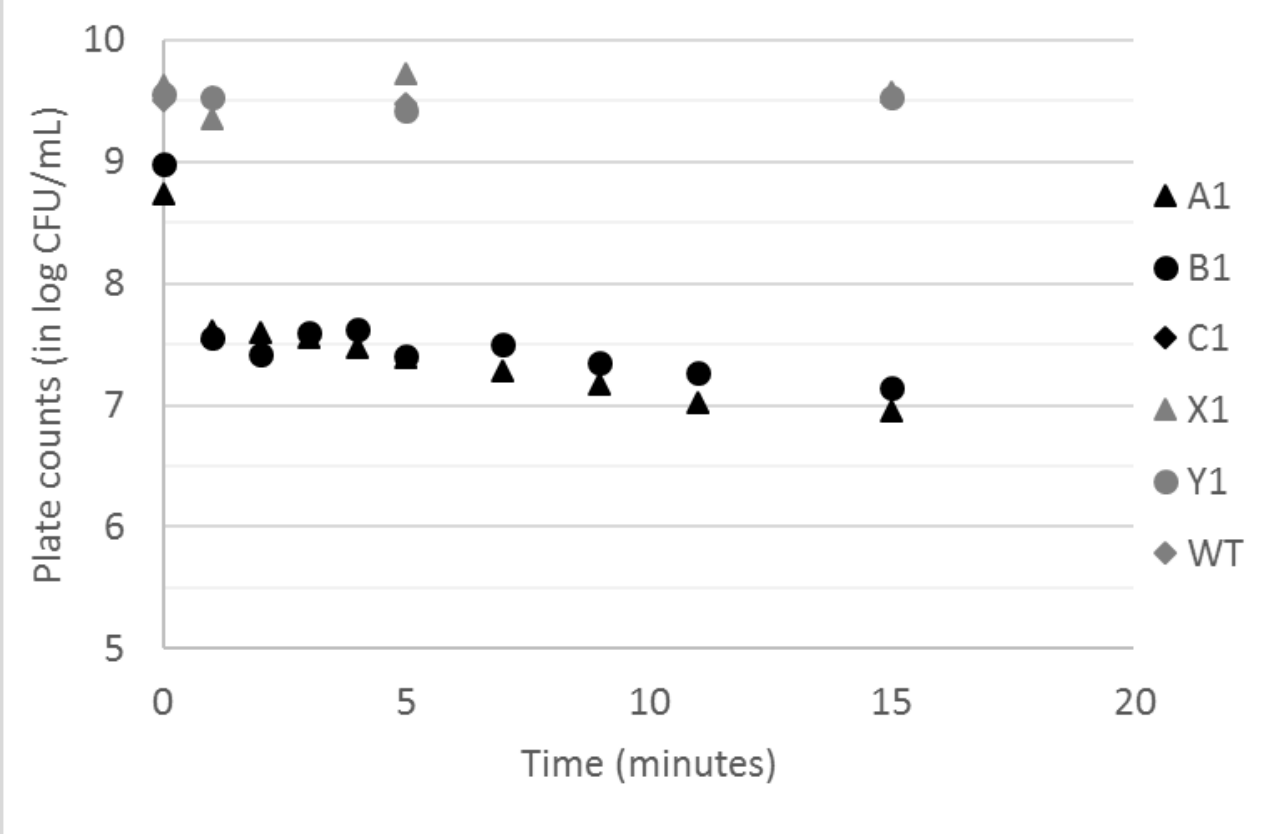


Figure 5

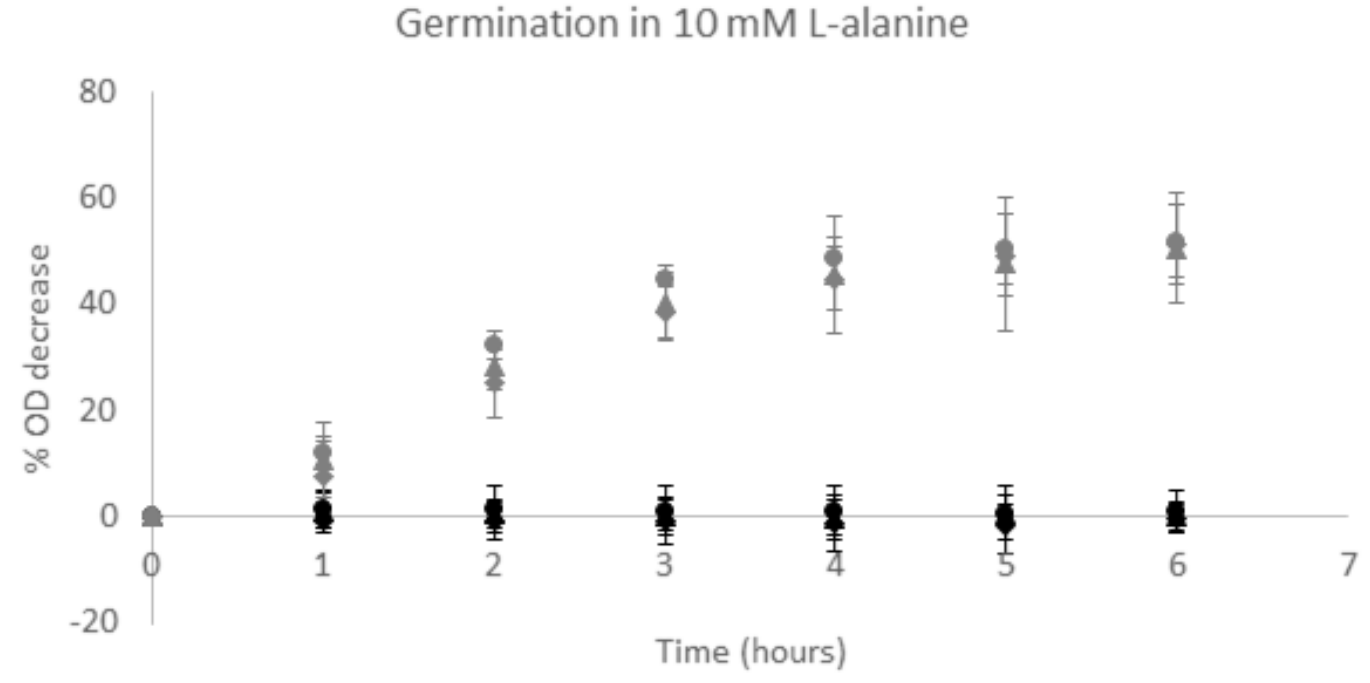

Germination in $100 \mathrm{mM} \mathrm{L-alanine}$

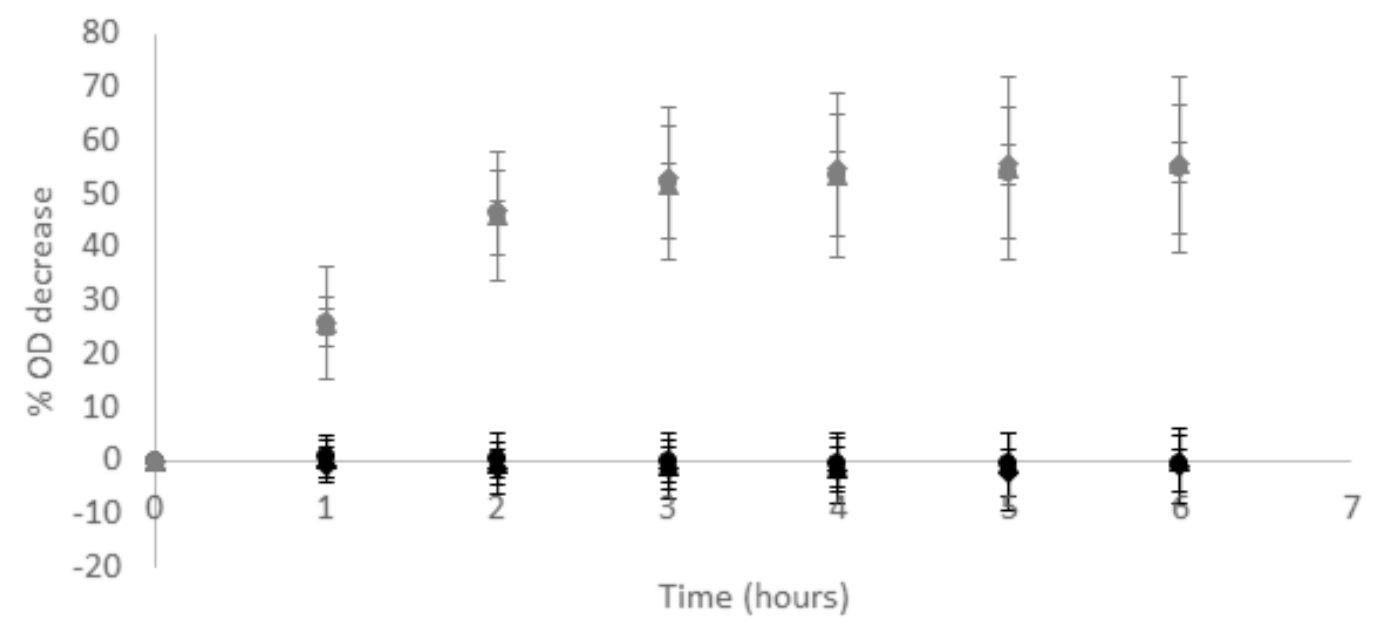


Figure 6

\section{Wild type (Total $n=6,675$ )}

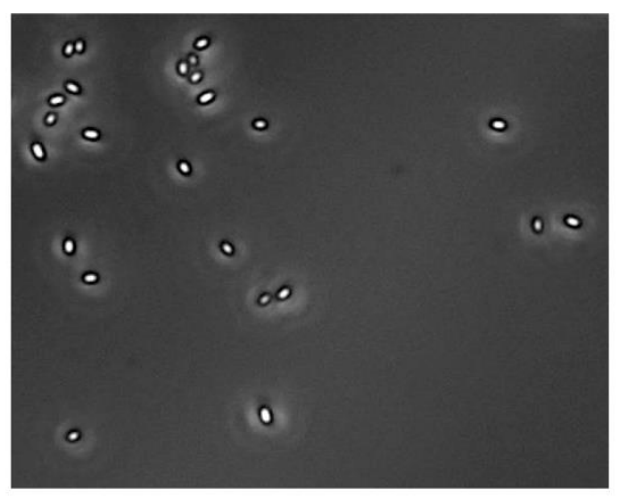

Phase dark

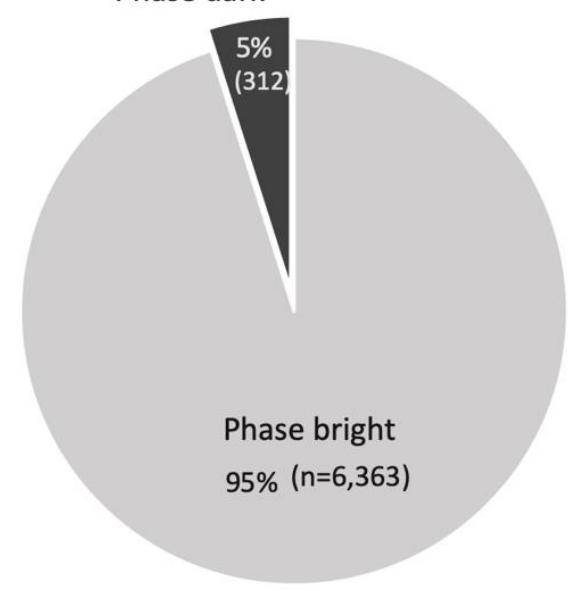

$\%$ Germinated; wild type

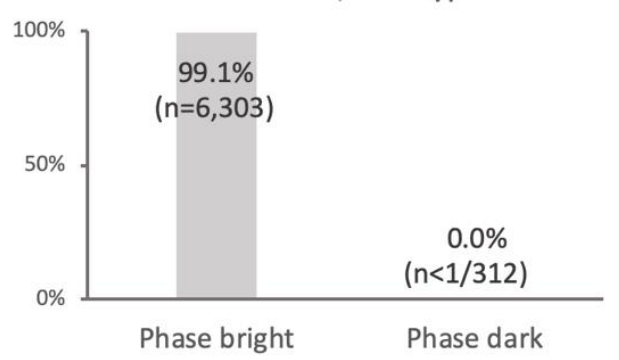

\section{A1 (Total $n=6,579$ )}

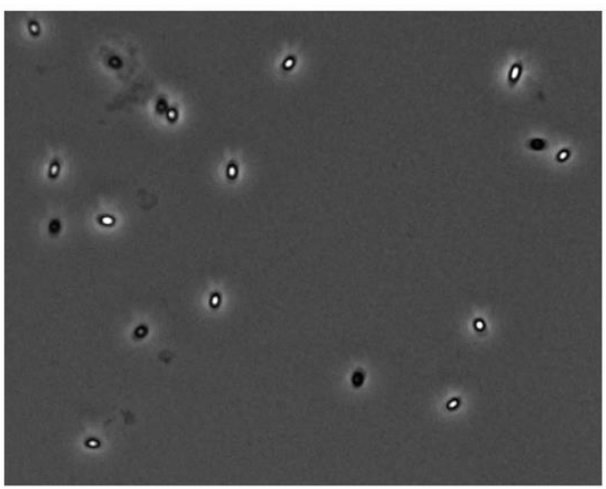

Phase grey

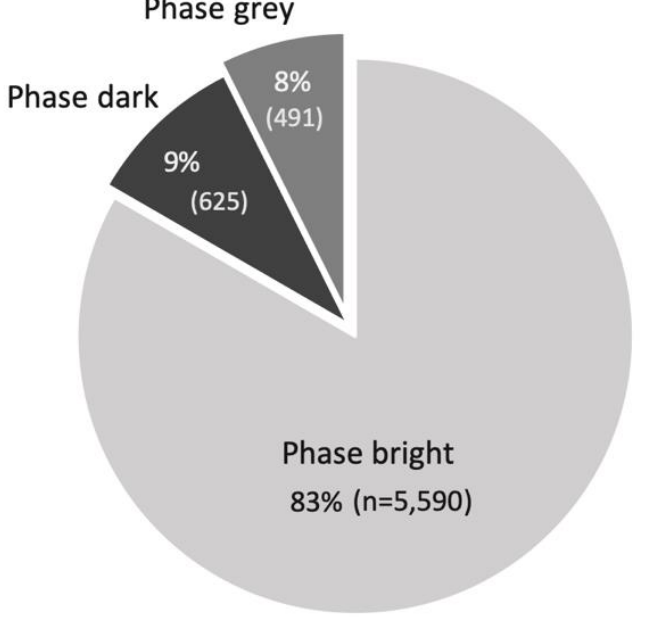

\% Germinated; A1

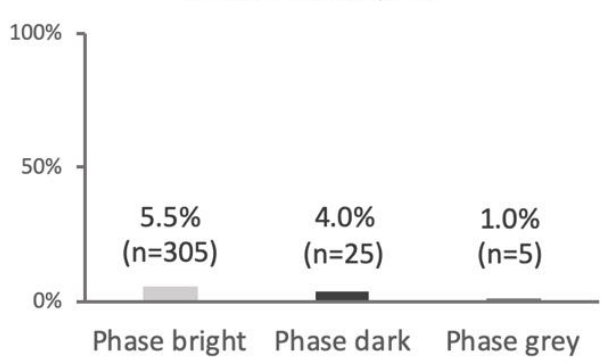


Figure 7

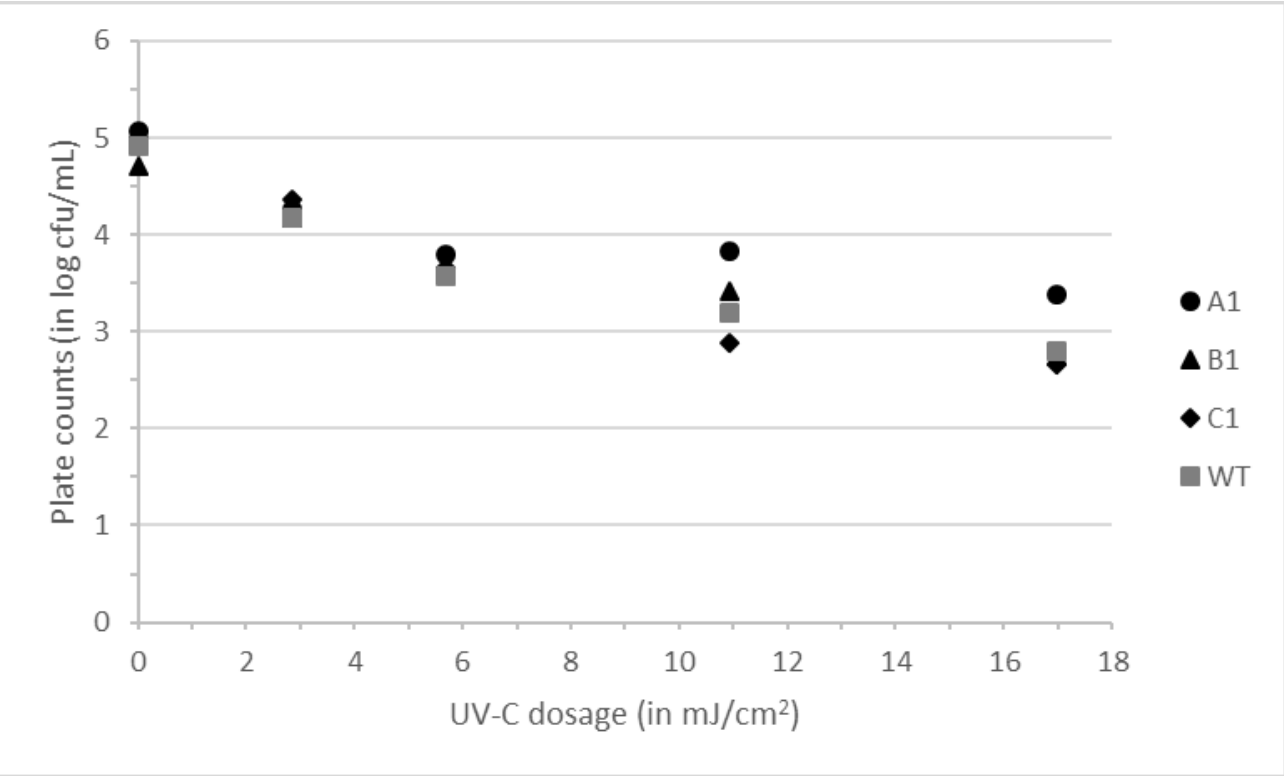


Highlights:

- B. cereus endospore UV-C resistance is a readily evolvable trait

- UV-C resistant mutant endospores display germination defects and heat sensitivity

- Endospore UV-C resistance is not transmitted to vegetative cell level 